\title{
Male involvement in Birth Preparedness and Complication Readiness in Ethiopia: A Systematic Review and Meta-analysis
}

Chilot kassa Mekonnen ( $\sim$ chilotkassa.m@gmail.com )

University of Gondar College of Medicine and Health Sciences

Hailemichael Kindie Abate

University of Gondar College of Medicine and Health Sciences

Negesu Gizaw Demessie

University of Gondar College of Medicine and Health Sciences

Research article

Keywords: Male involvement, birth preparedness, complication readiness, Ethiopia

Posted Date: August 24th, 2020

DOI: https://doi.org/10.21203/rs.3.rs-55935/v1

License: (1) (i) This work is licensed under a Creative Commons Attribution 4.0 International License.

Read Full License 


\section{Abstract}

Background: Maternal death may occur from complications while a woman is pregnant, during labor and post-partum period. Birth preparedness and complication readiness during pregnancy period prominently increase positive maternal as well as child health outcomes. Male involvement in pregnancy, labor and post-partum care has been shown to improve maternal and newborn outcomes. Nevertheless, it continues to be low, especially in low income countries. One of the reasons is the lack of birth preparedness and complication readiness, which is recognized as the most cost-effective and achievable components of safe motherhood programs around the world. Thus, this systematic review and meta-analysis study tried to determine the pooled prevalence of male involvement in birth preparedness and complication readiness (BP/CR) and its associated factors in Ethiopia.

Methods: Searching of the primary articles was completed by PubMed/MEDLINE, EMBASE, CINAHAL, and Google Scholar, HINARI portal which includes the SCOPUS, African Index Medicus, and African Journals Online Database. The data was extracted by using a standard data extraction checklist that developed according to Joanna Briggs Institute (JBI). For assessing heterogeneity across the studies $\mathrm{I}^{2}$ statistics was used. The Funnel plot asymmetry and Egger's tests were used to check the presence of publication bias. A random effect model was used to estimate the pooled prevalence of male involvement in birth preparedness and complication readiness. Odds Ratio (OR) with the $95 \%$ confidence interval was also used to determine the association of identified factors with the outcome variable. Statistical analysis was conducted using STATA version 11 software.

Result: From a total of 614, primary studies with (sample participants 3413), 8 were eligible for inclusion in the final systematic Review and meta-analysis. The pooled estimate of male involvement in birth preparedness and complication readiness was found to be $40.17 \%$ [95\% Cl (24.01-56.33)

Conclusion: The pooled prevalence of male involvement in birth preparedness and complication readiness was relatively low. Thus, Minister of Health with its stake holders better to give emphasis on community awareness programs so as to increase male involvement for birth preparedness and complication readiness.

\section{Background}

Birth preparedness and complication readiness (BP/CR) is a wide-ranging and inclusive package aimed at encouraging timely access to skilled maternal and neonatal services, promotes active preparation and decision making for delivery by pregnant women and their families[1]. Maternal mortality is one of the most important markers of health inequalities in low, middle and high-income countries and remains a major contributor to unmet public health concerns worldwide [2]. The 2015 World Health Organization report, indicated that more than half a million women were dying each year from the complications of pregnancy and childbirth, in which $99 \%$ of these deaths occurring in the developing world [3]. Besides this, 
for every 100,000 live births, 240 women died during pregnancy, childbirth, or the postpartum period which are mostly from developed countries $[4,5]$. There are notable disparities between and within countries in maternal deaths, with wide variations between rich and poor, urban and rural areas particularly in sub-Saharan Africa [6, 7].

A male companion at antenatal care is rare and in many communities, it is unthinkable to find male companions accompanying a woman to the labor room during delivery. Thus male involvement in reproductive health has been promoted as a promising new strategy for improving maternal and child health $[8,9]$. Although, birth preparedness and complication readiness is among the common approaches in employment for implementing safe motherhood programs, it may be hindered by male partners involvement since husbands had been the most influential decision-makers and as the key member of the family $[10,11]$. According to the Ethiopian Federal Ministry of Health, health and health related indicators $82.20 \%$ coverage for ANC, only $18.4 \%$ of the deliveries are attended by health professionals, $42.10 \%$ for postnatal care coverage [12].

Internationally, there was an estimated 303,000 maternal deaths happen maternal deaths happen year after year from pregnancy and childbirth related complications. About $99 \%$ of these deaths happen in underdeveloped countries and the great portion (62\%) belongs to the sub-Saharan Africa region [6] . The death of mothers might happen from unexpected emerging complications that happened while the women are pregnant, during labor, or in post-partum period. Birth preparedness and complication readiness during pregnancy period prominently increase positive maternal as well as child health outcomes [13].

Globally, around 1500 women die every day from complications related to pregnancy and childbirth [[4, 5, 14]. Globally, nearly $80 \%$ of the maternal morbidity and mortality are directly linked to pregnancy and childbirth complications. Different kinds of evidence showed that the commonest causes of maternal death among women in low-income and middle-income countries differ noticeably according to region. For example; In Africa, hemorrhage causes a third of maternal deaths. However, hypertensive disorders are the most common cause of maternal mortality in Latin American countries[5, 15]. Other major causes of death sepsis, obstructed labor, and complications from abortion also vary by geography $[6,16]$. Obstetric related complications including severe hemorrhage, infection, hypertensive disorders, sepsis and obstructed labor, and unsafe abortion are among the key factors to maternal death [3]. Although, there is significantly declined in Abortion and infection related maternal deaths in the last decade, Obstructed labor, hypertensive disorders and hemorrhage continues to be the major cause of maternal deaths[16]. About 125,000 women and 870,000 neonates die every year in Africa, predominantly in the first week of post-partum period. The country Ethiopia, is one of six countries sharing $50 \%$ of the total global burden of maternal mortality[17]. Male involvement in pregnancy and labor care has been shown to improve maternal and newborn outcomes. Nevertheless, it continues to be low, especially in low income countries. Numerous strategies have been suggested aimed at backup male involvement in reproductive health and maternity care, nonetheless no assessment has been made in terms of their effectiveness $[8,13,18]$. One of the reasons is the lack of birth preparedness and complication readiness, 
which is recognized as the most cost-effective and achievable components of safe motherhood programs around the world[1, 19]. Due to this and that reason mothers who are productive and basis for countries development through delivering and growing new generation might be morbid and die. This in turn could drain individuals, families pocket and countries budget at large unless the level of male involvement at each spot of maternal care improved. Thus, this systematic review and meta-analysis study tried to determine the pooled prevalence of male involvement in birth preparedness and complication readiness (BP/CR) and its associated factors in Ethiopia.

\section{Methods}

\section{Reporting of the result}

The preferred reporting Items for systematic Reviews and Meta-analysis (PRISMA) guideline were used to report the result of this systematic reviews and Meta-analysis.

\section{Data bases and Searching strategy}

We searched through PubMed, Web of Science Excerpt Medica Database (EMBASE), Google Scholar and psycEXTRA database for all available studies using the following search terms: "Male involvement";"Birth preparedness"; "Complication readiness"; "Factors"; *determinants*; *predictors*; and "Ethiopia”. In this systematic Reviews and Meta-analysis the search string was developed using "AND" and "OR". The Gerry literatures were also searched from Ethiopian's Universities (Jimma, Gondar, and Addis Ababa) research repository online library. In addition, a manual search of the references lists included was performed so as to address all evidences.

\section{Inclusion and exclusion criteria}

The studies were included in this review and meta-analysis if and only: they met the following criteria:(1) Crossectional observational studies, (2) Studies conducted in Ethiopia,(3) Studies that clearly reported the proportion of male involvement and complication readiness and/or factors (4) both published and unpublished studies at any time: Those studies with no clear report of the outcome ,program evaluation studies, qualitative studies and citations without full text were excluded from the review and metaanalysis.

\section{Study selection and quality assessment}

All the retrieved studies were exported to Endnote version 7 (Thomason Reuters, London) reference manager and duplicated studies were carefully removed. Three investigators (CKM, NGD and HKA) 
independently screened the titles and abstracts which were followed by a full-text review to determine the eligibility of each study. The disagreement was solved by consensus.

The quality of each study was evaluated by using Joanna Briggs Institute (JBI) quality appraisal criteria adapted for studies reporting prevalence data, Crossectional studies, and case control studies [20].

\section{Data extraction}

Data were independently extracted by two authors using standardized data extraction format that developed according to 2014 Joanna Briggs Institute Reviewers' Manual[21]. The tool includes Authors, Region, country, and study year, study design, sample size and proportion of Male involvement in birth preparedness and complication readiness in Ethiopia as well as associated factors. Articles that fulfilled the predefined criteria were used as a source of data for the final analysis. The three independent reviewers (CKM, HKA and NGD) extracted the data by using Excel spread sheet and cross checked to insure consistency. Any discrepancy was solved through discussion and repeating the procedure to overcome the difference occurred during extracting each single study. The information regarding author, year of publication, study design, sample size, proportion/prevalence of male involvement in birth preparedness and complication readiness, and odds ratio (OR) for associated factors were extracted.

\section{Heterogeneity and publication bias}

The percentage of total variation across studies due to heterogeneity was assessed by using $\mathrm{I}^{2}$ statistics[22]. The value of $\mathrm{I}^{2}, 25,50$, and $75 \%$ represented low, moderate, and high heterogeneity respectively. Funnel plot and Egger's regression test was done to check whether publication bias exists or not across studies [23]. Visual examination of funnel plot asymmetry, Begg-Mazumdar Rank correlation tests and Egger's regression tests were utilized to check for publication bias [23]

\section{Data Analysis}

The overall pooled proportion of male involvement was estimated using random effect model. The pooled odds ratio (OR) of knowledge of pregnancy danger signs, previous pregnancy and post-partum complication was done. Subgroup analysis was done based regional location in the country to adjust the variation in the pooled estimate of the prevalence/proportion of male involvement in birth preparedness and complication readiness. STATA version 11 (Stata Corp, College Station, TX, USA) statistical software was used for all statistical analysis. The Begg and Egger's weighted regression method were used to detect evidence of publication bias. The $p$-value of $\leq 0.05$ was considered as presence of significant publication bias.

\section{Result}




\section{Selection and identification of articles}

A total of 614 with (3413 participants) were retrieved through from electronic databases and other sources. The title and abstract of every study was screened and duplicated or irrelevant articles were removed using EndNote Version7 software. Doing these, 146 articles were removed due to duplication and the remaining 468 articles, 460 were removed due to their title and abstracts was not in-line with our inclusion criteria( did not correctly report the correct outcome, studies conducted outside of Ethiopia). Finally, a total of only 8 articles were included for this systematic review and meta-analysis (Fig.1).

\section{Description of the included studies}

We included a total of 8 crossectional observational studies with 3413 participants in the final systematic review and meta-analysis. The smallest sample size was 233 in the study conducted from Southern Nations and nationalities region of Ethiopia[24]. Whereas, the largest sample size, was 824 from the study conducted in the Amhara region, Ethiopia. The detailed characteristics of the included studies were presented (Table1). In the current systematic review and meta-analysis, four regions and one administrative town in the country were included. Three studies were from Tigray [25-27], two were from Oromia region $[28,29]$.

Table 1

Descriptive summary of eight studies included in the final systematic review and meta-analysis overall male involvement in birth preparedness and complication readiness in Ethiopia

\begin{tabular}{|c|c|c|c|c|c|c|c|}
\hline Author & Year & Design & Region & Sample & $r(p w o)$ & Proportion(p) & $\begin{array}{l}\text { NOS } \\
\text { Score }\end{array}$ \\
\hline $\begin{array}{l}\text { Destaw et al. } \\
{[30]}\end{array}$ & 2014 & Crossectional & $\begin{array}{l}\text { Addis } \\
\text { Ababa }\end{array}$ & 403 & 264 & 65.5 & 5 \\
\hline $\begin{array}{l}\text { Demessie et al. } \\
\text { [28] }\end{array}$ & 2016 & Crossectional & Oromia & 374 & 224 & 50.8 & 6 \\
\hline Tantu et al.[29] & 2018 & Crossectional & Oromia & 421 & 127 & 30.2 & 7 \\
\hline Baraki et al. [31] & 2019 & Crossectional & Tigray & 399 & 187 & 46.9 & 7 \\
\hline $\begin{array}{l}\text { Weldearegay et } \\
\text { al.[25] }\end{array}$ & 2015 & Crossectional & Tigray & 376 & 227 & 60.4 & 6 \\
\hline $\begin{array}{l}\text { Mersha et al. } \\
\text { [32] }\end{array}$ & 2016 & Crossectional & Amhara & 824 & 82 & 10 & 6 \\
\hline $\begin{array}{l}\text { Gebrehiwot et } \\
\text { al.[26] }\end{array}$ & 2013 & Crossectional & Tigray & 376 & 101 & 26.9 & 7 \\
\hline Paulos et al.[24] & 2020 & Crossectional & SNNPR & 233 & 72 & 30.9 & 6 \\
\hline
\end{tabular}




\section{Male involvement in birth preparedness and complication readiness}

\section{Overall involvement in birth preparedness and complication readiness}

From a total of 8 studies [24-26, 28-32] crossectional observational studies, all studies provided information on overall involvement of males in birth preparedness and complication readiness. As stated in the forest plot (Fig.2), the pooled estimate of overall male involvement was $40.17 \%$ [95\% Cl (24.0156.33)]. High heterogeneity was observed (I-squared $=99.2 \%)$, however there was no an evidence to show publication bias using Egger's statistical test ( $p$-value $=0.258$ ) (Table2). For reducing the potential random variations between the included studies, we conducted a sub-group analysis by region where the primary studies conducted. According to the sub-group analysis the highest proportion of male involvement was observed from Addis Ababa65.5\% [95\% Cl (60.86-70.14)], followed by Tigray $44.71 \%$ [ $95 \% \mathrm{Cl}(25.29-$ 64.13)] (Fig.3).

Table 2

Egger's and Begg's Tests to assess publication bias of eight included for overall analysis of birth preparedness and complication readiness

\begin{tabular}{|llllll|}
\hline Std_Eff & Coef. & Std. Err. & $T$ & $\mathrm{p}>|\mathrm{t}|$ & [95\% Conf. Interval] \\
\hline Slope & 3.951501 & 3.164253 & 1.25 & 0.258 & $-3.791148-11.69415$ \\
\hline Bias & -39.61011 & 28.66138 & -1.38 & 0.216 & $-109.742-30.52175$ \\
\hline
\end{tabular}

A Meta regression analysis was done using year of study and sample size as covariate to explore the possible source of heterogeneity (Table3). But, there was no significant statistical evidence that show the presence of heterogeneity, which explained by using these two variables

Table 3

Table 3: Meta-regression analysis for eight included studies for overall analysis of birth preparedness and complication readiness

\begin{tabular}{|llllll|}
\hline Logp & Coef. & Std. Err. & $\mathrm{T}$ & $\mathrm{p}>|\mathrm{t}|$ & [95\%Conf. Interval] \\
\hline Year of study & -.0284132 & .4516844 & -0.06 & 0.952 & $-1.189505-1.132678$ \\
Sample size & -.0030312 & .0031921 & -0.95 & 0.386 & $-0.0112369-0.0051744$ \\
Constant & 62.11284 & 909.9485 & 0.07 & 0.948 & $-2276.984-2401.21$ \\
\hline
\end{tabular}


In addition, sensitivity analysis was conducted by using a random effect model to identify the effect of single study on overall pooled estimate. The analysis showed that there was no evidence of single study influence on overall pooled estimate (Fig.4).

\section{Male involvement in three main domains (Antenatal, delivery, and post-partum)}

In this systematic review and meta-analysis, we measure male involvement using three domains such as involvement during antenatal care (ANC), during delivery, and post-partum period. Accordingly, eight studies [24-26, 28-32] which reported antenatal care involvement were included in the pooled analysis of male involvement during ANC. In this meta-analysis, the proportions of pooled male involvement during antenatal care were found to be $41.14 \%$ [95\% Cl (23.68-58.60)] (Fig.7).Whereas, male involvement during delivery and post-partum period was found unfortunately similar with the pooled proportion of $45.56 \%$ [95\% Cl (28.82-62.13)] (Fig.9\&11). High heterogeneity was observed (I-squared=99.3\%, p $\leq 0.001)$, for reducing the potential random variations between the included studies, we conducted a sub-group analysis by region where the primary studies conducted. According to the sub-group analysis the highest proportion of male involvement during ANC was observed from Addis Ababa 73.2\% [95\% Cl (68.88-77.52)] followed by Tigray $44.71 \%$ [95\% Cl (25.29-64.13)] (Fig.8).

We found Six studies $[25,26,28,29,31,32]$ that describe about male involvement during delivery and post-partum periods from three regions of Ethiopia(Oromia, Amhara, and Tigray). Similarly there was high heterogeneity for delivery and post-partum involvements (l-squared $=98.9 \%, p \leq 0.0001$ ). Having this in mind we have done sub-group analysis by region and we found that the highest proportion of male involvement during delivery and post-partum period was reported from Tigray region of Ethiopia $51.09 \%$ [95\% Cl(23.55-78.64)] followed by $47.23 \%[95 \% \mathrm{Cl}(14.60-79.87)]$ in Oromia region of Ethiopia(Fig.12). We have also done the statistical tests of Egger's and Begg's to assess publication bias for the included studies in the Meta-analysis of male involvement during delivery and post-partum period. There was no evidence of bias ( $p$-value>0.069) (Table6). We have performed meta-regression by using year of study and sample size as a covariate (Table7).

\section{Factors associated with male involvement in birth preparedness and complication readiness.}

Among the variables included in the meta-analysis husband's level of education was found to be statistically significant in three studies $[28,29,32]$. However, the pooled odds ratio found to be borderline statistically significant with [OR=1.27, 95\% $\mathrm{Cl}(0.26-6.30)]$ (Fig.15). The distance from health facilities was also statistically significant in three primary studies [24, 29,32]. But, it was also borderline significant [OR=0.75, 95\% Cl (0.10-5.83)] (Fig.16). Moreover the husband's knowledge of at least one danger sign during pregnancy was statistically significant in four included primary articles $[25,28,29,32]$. The pooled odds ratio was found to be border line significant [OR=3.18, 95\% Cl [(0.54-18.66)] with male involvement 
for birth preparedness and complication readiness (Fig.17). The husband's knowledge of danger signs during delivery was also found to be significant in two primary studies[25,32]. However, the pooled odds ratio was found to be borderline significant [OR=4.60, 95\% $\mathrm{Cl}(0.06-375.06)]$ predictors of male involvement in birth preparedness and complication readiness (Fig.18). Similarly husband's knowledge about post-partum danger signs was found to be [OR $=2.50,95 \% \mathrm{Cl}(0.06-104.65)]$ with involvement in birth preparedness and complication readiness (Fig.19). Husband's attendance of at least one ANC visit with their wives was found to be [OR=3.20,95\% $\mathrm{Cl}(1.97-5.19)]$ statistically significant predictor of male involvement (Fig.20).

Table 4

Egger's and Begg's test for studies included in the analysis of Antenatal care involvement of males

Egger's test

\begin{tabular}{r|rcccrr}
\hline Std_Eff & Coef. & Std. Err. & $t$ & $\mathrm{P}>|\mathrm{t}|$ & [95\% Conf. & Interva1] \\
\hline slope & $\mathbf{1 . 3 3 7 6 4 2}$ & $\mathbf{. 3 8 8 2 2 9 7}$ & $\mathbf{3 . 4 5}$ & $\mathbf{0 . 0 1 4}$ & $\mathbf{. 3 8 7 6 7 8 3}$ & $\mathbf{2 . 2 8 7 6 0 6}$ \\
bias & $\mathbf{. 9 7 9 5 7 4 1}$ & $\mathbf{. 1 9 8 3 4 3 9}$ & $\mathbf{4 . 9 4}$ & $\mathbf{0 . 0 0 3}$ & $\mathbf{. 4 9 4 2 4 4}$ & $\mathbf{1 . 4 6 4 9 0 4}$ \\
\hline
\end{tabular}

Table 5

Meta-regression of eight included studies for the meta-analysis of male involvement during antenatal period.

\begin{tabular}{r|rccccr}
\hline logp & Coef. & std. Err. & $\tau$ & $\mathrm{P}>|\tau|$ & \multicolumn{2}{c}{ [95\% Conf. Interva1] } \\
\hline yearofstudy & -.0375768 & $\mathbf{. 4 4 9 7 6 3 9}$ & $-\mathbf{0 . 0 8}$ & $\mathbf{0 . 9 3 7}$ & $\mathbf{- 1 . 1 9 3 7 3 2}$ & $\mathbf{1 . 1 1 8 5 7 8}$ \\
sample & -.0030746 & $\mathbf{. 0 0 3 1 8 6 1}$ & $\mathbf{- 0 . 9 7}$ & $\mathbf{0 . 3 7 9}$ & -.0112647 & $\mathbf{0 0 5 1 1 5 5}$ \\
_cons & $\mathbf{8 0 . 6 2 4 8 6}$ & $\mathbf{9 0 6 . 0 5 8}$ & $\mathbf{0 . 0 9}$ & $\mathbf{0 . 9 3 3}$ & $\mathbf{- 2 2 4 8 . 4 7 1}$ & $\mathbf{2 4 0 9 . 7 2 1}$ \\
\hline
\end{tabular}

Table 6

Egger's and Begg's test for studies included in delivery\& post-partum

Egger's test

\begin{tabular}{r|rcccrr}
\hline Std_Eff & Coef. & std. Err. & $t$ & $\mathrm{P}>|\mathrm{t}|$ & [95\% Conf. & Interval] \\
\hline slope & $\mathbf{9 0 0 5 9}$ & $\mathbf{. 3 6 4 7 5 5 5}$ & $\mathbf{2 . 4 7}$ & $\mathbf{0 . 0 6 9}$ & $\mathbf{- . 1 1 2 1 3 3 7}$ & $\mathbf{1 . 9 1 3 3 1 4}$ \\
bias & $\mathbf{. 3 2 3 2 0 0 9}$ & $\mathbf{. 1 7 2 1 8 5 2}$ & $\mathbf{1 . 8 8}$ & $\mathbf{0 . 1 3 4}$ & $\mathbf{- . 1 5 4 8 6 2}$ & $\mathbf{. 8 0 1 2 6 3 8}$ \\
\hline
\end{tabular}

Table 7

Meta-regression six included studies for delivery and post-partum involvement 


\begin{tabular}{r|rccccr}
\hline logp & Coef. & std. Err. & $t$ & $\mathrm{P}>|\mathrm{t}|$ & \multicolumn{2}{c}{ [95\% Conf. Interva1] } \\
\hline yearofstudy & $\mathbf{. 0 0 0 4 0 9 3}$ & $\mathbf{. 5 0 5 5 1 6}$ & $\mathbf{0 . 0 0}$ & $\mathbf{0 . 9 9 9}$ & $\mathbf{- 1 . 6 0 8 3 6 8}$ & $\mathbf{1 . 6 0 9 1 8 7}$ \\
sample & -.0005577 & $\mathbf{0 0 4 3 7 8 2}$ & $-\mathbf{0 . 1 3}$ & $\mathbf{0 . 9 0 7}$ & $\mathbf{- . 0 1 4 4 9 1 1}$ & $\mathbf{0 1 3 3 7 5 8}$ \\
_cons & $\mathbf{1 . 0 4 3 6 7 4}$ & $\mathbf{1 0 1 8 . 3 6 3}$ & $\mathbf{0 . 0 0}$ & $\mathbf{0 . 9 9 9}$ & $\mathbf{- 3 2 3 9 . 8 4 1}$ & $\mathbf{3 2 4 1 . 9 2 8}$ \\
\hline
\end{tabular}

\section{Discussion}

This systematic review and meta-analysis was conducted to assess male involvement in birth preparedness and complication readiness with its major components. The overall pooled estimate of male involvement in birth preparedness and complication readiness was found to be $40.17 \%$ [95\% Cl(24.01-56.33)]. This result was in line with the studies conducted in Uganda (40.82\%) and $\mathrm{Nepal}(50.49 \%)$ respectively $[33,34]$. It was also consistent with another study conducted in Nepal in which (50.07\%) of males were involved in birth preparedness [35].

This meta-analysis study result was higher than the study conducted in Northern Nigeria (32.1\%) of males were involved in birth preparedness and complication readiness[27]. The possible explanation might be due to the fact that there was time gap between the current study and Nigeria that was in 2010 . The finding was lower than the study conducted in Per-Urban Northern Uganda in which (65.4\%) males were involved in accessing the skilled birth delivery [36]. The possible explanation might be due to the fact that the socio-demographic variation because the study in Uganda was conducted only in the urban. Male involvement has a great impact on maternal and child health during pregnancy, labor and postpartum [18]. The meta-analysis result of male involvement during ANC 41.1\%[95\% Cl(23.68-58.60)] was in line with the study conducted in Rural Uganda which was $29.4 \%$ of males were involved during antenatal care of their wives[37]. It was also found consistent with the study conducted in Nepal in which $48.0 \%$ of males were involved during ANC period.[34]. Similarly the finding of this meta-analysis was in line with another study conducted in Nepal in which $39.3 \%$ of husband's were involved during ANC of their wives[35].

In this meta-analysis the pooled estimate of male involvement during delivery was found to be $45.56 \%$ [95\% Cl(28.82-62.13)] which was in line with the study conducted with the study conducted in Nepal[35] in which $47.9 \%$ of males were involved, but higher than the study conducted in Rural Uganda in which (22.3\%)of husbands were involved during delivery[37]. The possible explanation might be due to the fact that the study in Uganda was conducted in rural communities only, but not the meta-analysis. The finding of this meta-analysis was found lower than the study conducted in India in which $67.7 \%$ of males were involved during delivery[38].

In the current meta-analysis post-partum male involvement was found to be $45.56 \%[95 \% \mathrm{Cl}(28.82-62.13)]$ which was in line with the study conducted with the study conducted in Nepal[35] in which $47.9 \%$ of males were involved. But, lower than the study conducted in India in which $67.4 \%$ of the husbands were involved during post-partum period[38]. The possible explanation might be socio-demographic variations 
and the size of the studies could bring the discrepancy. Male involvement during the three domains (ANC, delivery, and post-partum periods) played a significant role to healthy maternal and child outcomes. This claim has been supported by a systematic and meta-analysis studies [18, 39]. Husband's attendance of at least one ANC visit with their wives was found to be three times more likely to involve as compared with no attended at all. The possible explanation might be those who attend at least once could have an insight about the importance of their involvement that not attending at all.

\section{Limitation Of The Study}

This systematic review and meta-analysis included only articles reporting in English language, which may restrict our findings. The majority of the articles use small sample size, might be affect the prevalence estimation. All included studies were cross sectional study design in which the result might potentially affected by confounding variables. In addition the meta-analysis didn't include all regions which only include four regions and one administrative city of the country. Therefore; further country based studies to assess other factors related to health service, health policy and health care giver related factors for the involvement of males in birth preparedness and complication readiness, in Ethiopia are recommended.

\section{Conclusion}

The overall proportion of male involvement for birth preparedness and complication readiness was found to be low. Husband's attendance of at least one antenatal visit was found to be significant predictor of male involvement. Therefore, Minister of Health with its stake holders should emphasis on community and institution based programs in the manner to improve male involvement to bring positive maternal and child health outcomes.

\section{Abbreviations}

ANC; Antenatal Care, Cl; Confidence Interval, OR; Odds Ratio, SNNR; Southern Nations and Nationality Region,

\section{Declarations}

\section{Ethics approval and consent to participate}

Not applicable

\section{Consent for publication}

Not applicable 


\section{Availability of data and materials}

Data will be available from the corresponding author upon reasonable request.

\section{Competing interests}

We all the authors ascertained that there is no competing interest concerning this manuscript.

\section{Funding}

No funding was obtained for this study.

\section{Authors' contributions}

CKM developed the protocol and involved in the design, selection of study, data extraction, statistical analysis and developing the initial drafts of the manuscript. HKA and NGD involved in quality assessment. CKM, HKA and NGD prepared and revising subsequent drafts as well as prepared the final draft of the manuscript. We authors read and ascertained the final draft of this manuscript.

\section{Acknowledgments}

Not applicable.

\section{References}

1. McPherson RA, et al. Are birth-preparedness programmes effective? Results from a field trial in Siraha district, Nepal. J Health Popul Nutr. 2006;24(4):479.

2. Ayebare $E$, et al. Interventions for male involvement in pregnancy and labour: a systematic review. African Journal of Midwifery Women's Health. 2015;9(1):23-8.

3. WHO, U. and

WHO, U. and. UNFPA W, UNPD. Trends in Maternal Mortality: 1990 to 2015: Estimates Developed by WHO, UNICEF. UNFPA, The World Bank and the United Nations Population Divisions. Who/Rhr/1523 [Internet], 2015. 32(5): p. 1-55.

4. Oza S, et al. Neonatal cause-of-death estimates for the early and late neonatal periods for 194 countries: 2000-2013. Bull World Health Organ. 2014;93:19-28.

5. You D, et al. Global, regional, and national levels and trends in under-5 mortality between 1990 and 2015, with scenario-based projections to 2030: a systematic analysis by the UN Inter-agency Group for Child Mortality Estimation. The Lancet. 2015;386(10010):2275-86. 
6. Alkema L, et al. Global, regional, and national levels and trends in maternal mortality between 1990 and 2015, with scenario-based projections to 2030: a systematic analysis by the UN Maternal Mortality Estimation Inter-Agency Group. The Lancet. 2016;387(10017):462-74.

7. Berhan Y, Berhan A. Review of maternal mortality in Ethiopia: a story of the past 30 years. Ethiopian journal of health sciences. 2014;24:3-14.

8. Mangeni $\mathrm{JN}$, et al. Male involvement in maternal healthcare as a determinant of utilisation of skilled birth attendants in Kenya. East Afr Med J. 2012;89(11):372-83.

9. Rehfeldt GE, Development and verification of models of freezing tolerance for Douglas-fir populations in the Inland Northwest. Vol. 369. 1986: US Department of Agriculture, Forest Service, Intermountain Research Station.

10. Fastring D, Mayfield-Johnson S, Madison J. Evaluation of a health education intervention to improve knowledge, skills, behavioral intentions and resources associated with preventable determinants of infant mortality. Diversity equality in health care. 2017;14(6):290.

11. Nesane K, Maputle SM, Shilubane H. Male partners' views of involvement in maternal healthcare services at Makhado Municipality clinics, Limpopo Province, South Africa. African journal of primary health care family medicine. 2016;8(2):1-5.

12. Demographic CE. Health Survey-2011. Central Statistical Agency Addis Ababa. Ethiopia ICF International Calverton, Maryland, USA. 2012. 2016.

13. Mehari K, Wencheko E. Factors affecting maternal health care services utilization in rural Ethiopia: a study based on the 2011 EDHS data. Ethiopian Journal of Health Development. 2013;27(1):16-24.

14. Alkema L, et al. Child mortality estimation 2013: an overview of updates in estimation methods by the United Nations Inter-agency Group for Child Mortality Estimation. PloS one. 2014;9(7):e101112.

15. WHO, U., UNFPA, World Bank Group and the United Nations Population Division. Trends in maternal mortality: 1990 to 2015: estimates by WHO, UNICEF. 2015, UNFPA, World Bank group and the united nations population division.

16. Berhan Y, Berhan A. Causes of maternal mortality in Ethiopia: a significant decline in abortion related death. Ethiopian journal of health sciences. 2014;24:15-28.

17. Hiluf M, Fantahun M. Birth preparedness and complication readiness among women in Adigrat town, north Ethiopia. Ethiopian Journal of Health Development, 2008. 22(1): p. 14-20.

18. Yargawa J, Leonardi-Bee J. Male involvement and maternal health outcomes: systematic review and meta-analysis. J Epidemiol Community Health. 2015;69(6):604-12.

19. Ditekemena J, et al. Determinants of male involvement in maternal and child health services in subSaharan Africa: a review. Reproductive health. 2012;9(1):32.

20. Wells G, et al., The Newcastle-Ottawa Scale (NOS) for assessing the quality of nonrandomized studies in meta-analysis. Ottawa (ON): Ottawa Hospital Research Institute, 2011.[cited 2014 Mar 12]. 2012. 
21. Munn Z, et al. The development of a critical appraisal tool for use in systematic reviews addressing questions of prevalence. International journal of health policy management. 2014;3(3):123.

22. Huedo-Medina TB, et al. Assessing heterogeneity in meta-analysis: Q statistic or $\mathrm{I}^{2}$ index? Psychol Methods. 2006;11(2):193.

23. Rücker G, Schwarzer G, Carpenter J. Arcsine test for publication bias in meta-analyses with binary outcomes. Statistics in medicine. 2008;27(5):746-63.

24. Paulos K, et al. Male involvement in birth preparedness and complication readiness for emergency referral at Sodo town of Wolaita zone, South Ethiopia: a cross sectional study. BMC Pregnancy Childbirth. 2020;20(1):62.

25. Weldearegay HG. Determinant factors of male involvement in birth preparedness and complication readiness at Mekelle town; a community based study. Sci J Public Health. 2015;3(2):175-80.

26. Gebrehiwot H, Gebregziabher W, Gidey G. Assessment of Husbands' Participation on Birth Preparedness and Complication Readiness in Enderta Woreda, Tigray Region, Ethiopia, 2012. J Women's Health Care. 2013;3(140):2167-420.

27. Iliyasu Z, et al., Birth preparedness, complication readiness and fathers' participation in maternity care in a northern Nigerian community. African journal of reproductive health, 2010. 14(1).

28. Demissie DB, Bulto GA, Terfassa TG. Involvement of male in antenatal care, birth preparedness and complication readinessand associated factors in Ambo town, Ethiopia. Journal of Health Medicine Nursing. 2016;27(5):14-23.

29. Tantu Z, Teklemariam Gultie WE, Boti N. Husbands' participation in birth preparedness and complication readiness and associated factors in Kucha district, GamoGofa Zone, Southern Ethiopia..

30. Destaw A, Assessment of Husband Involvement during Pregnancy and Child Birth in AkakiKaliti Subcity, Addis Ababa, Ethiopia. 2014, Addis Abeba Universty.

31. Baraki Z, et al. Husbands involvement in birth preparedness and complication readiness in Axum town, Tigray region, Ethiopia, 2017. BMC Pregnancy Childbirth. 2019;19(1):180.

32. Mersha AG. Male involvement in the maternal health care system: implication towards decreasing the high burden of maternal mortality. BMC Pregnancy Childbirth. 2018;18(1):493.

33. Kakaire $\mathrm{O}$, Kaye DK, Osinde MO. Male involvement in birth preparedness and complication readiness for emergency obstetric referrals in rural Uganda. Reproductive health. 2011;8(1):12.

34. Bhusal CK, Bhattarai S. Involvement of male in birth preparedness in Tulsipur municipality of dang district, Nepal. Journal of Chitwan Medical College. 2015;5(4):33-8.

35. Bhatta DN. Involvement of males in antenatal care, birth preparedness, exclusive breast feeding and immunizations for children in Kathmandu, Nepal. BMC Pregnancy Childbirth. 2013;13(1):14.

36. Tweheyo R, et al. Male partner attendance of skilled antenatal care in peri-urban Gulu district, Northern Uganda. BMC Pregnancy Childbirth. 2010;10(1):53. 
37. Kalisa R, Malande 00, Birth preparedness, complication readiness and male partner involvement for obstetric emergencies in rural Rwanda. The Pan African medical journal, 2016. 25.

38. Kumar K. Birth Preparedness and Complication Readiness in Uttar Pradesh, India. Health. 2016;8(06):605.

39. Ditekemena J, et al. Determinants of male involvement in maternal and child health services in subSaharan Africa: a review. Reproductive health. 2012;9(1):1-8.

\section{Figures}

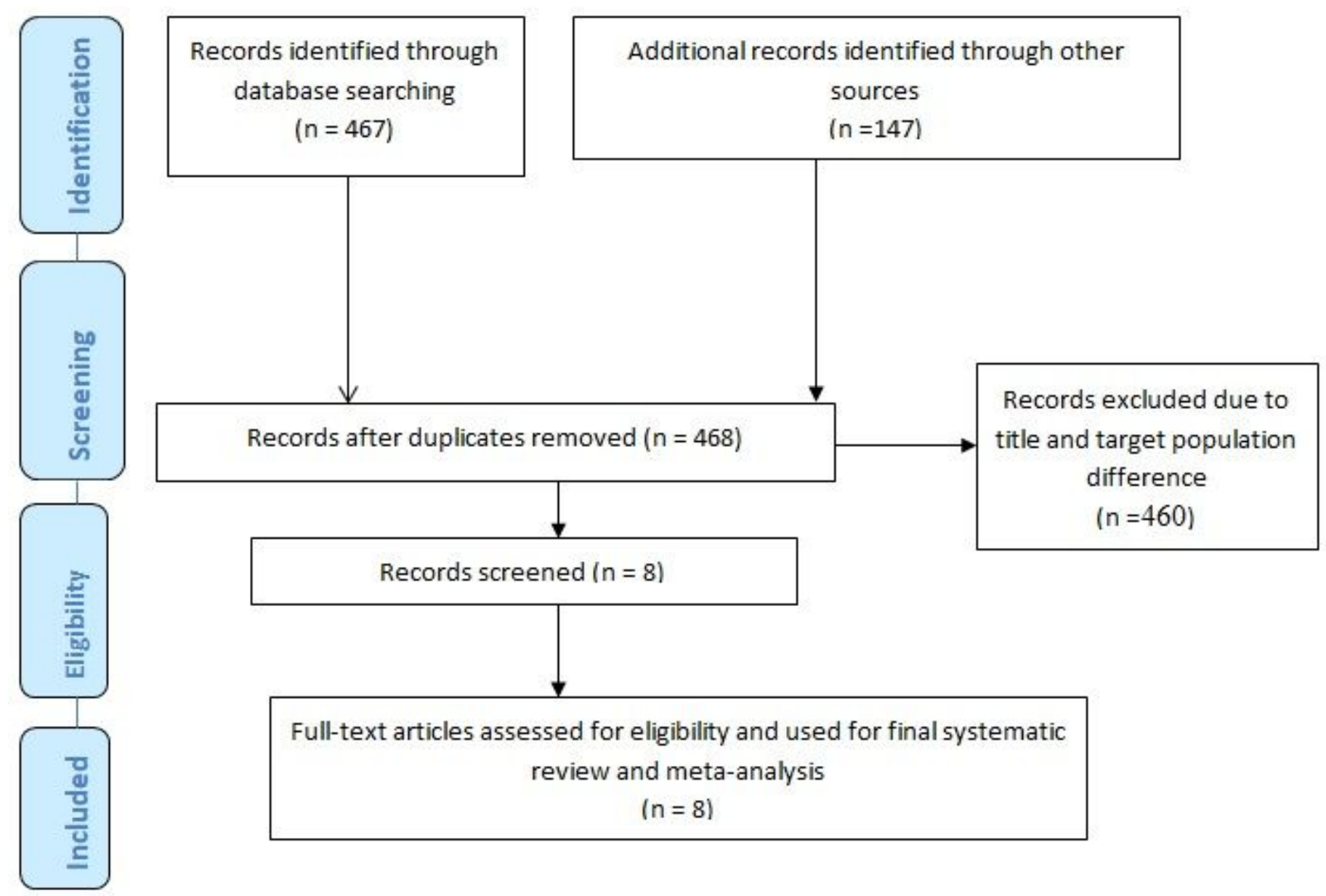

Figure 1

PRISMA flow diagram of included studies 


\section{Overall male involvement}

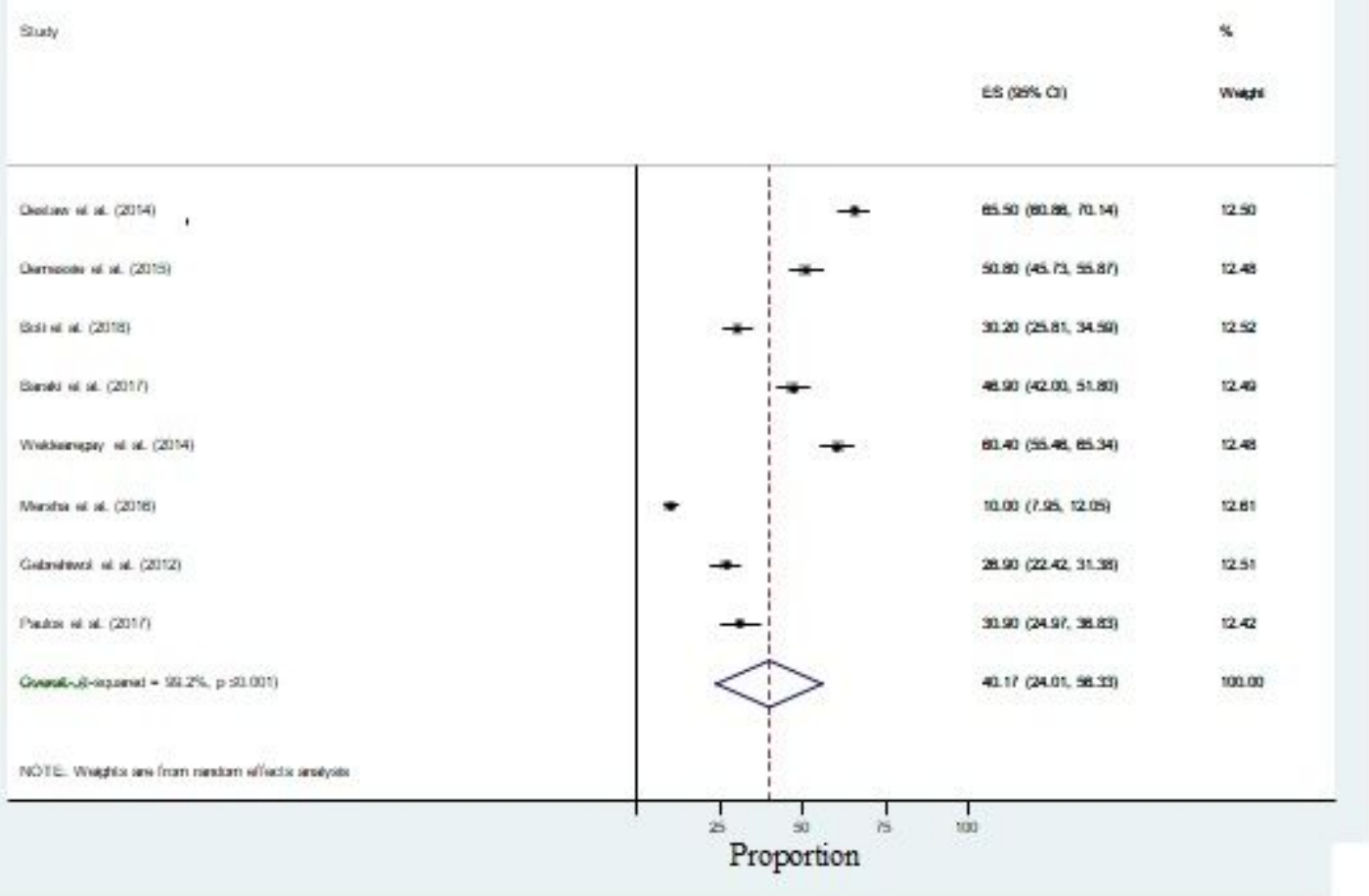

\section{Figure 2}

Meta-analysis (forest plot) for the overall all proportion of male involvement in birth preparedness and complication readiness in Ethiopia 
Sub-group analysis of male involvement by region

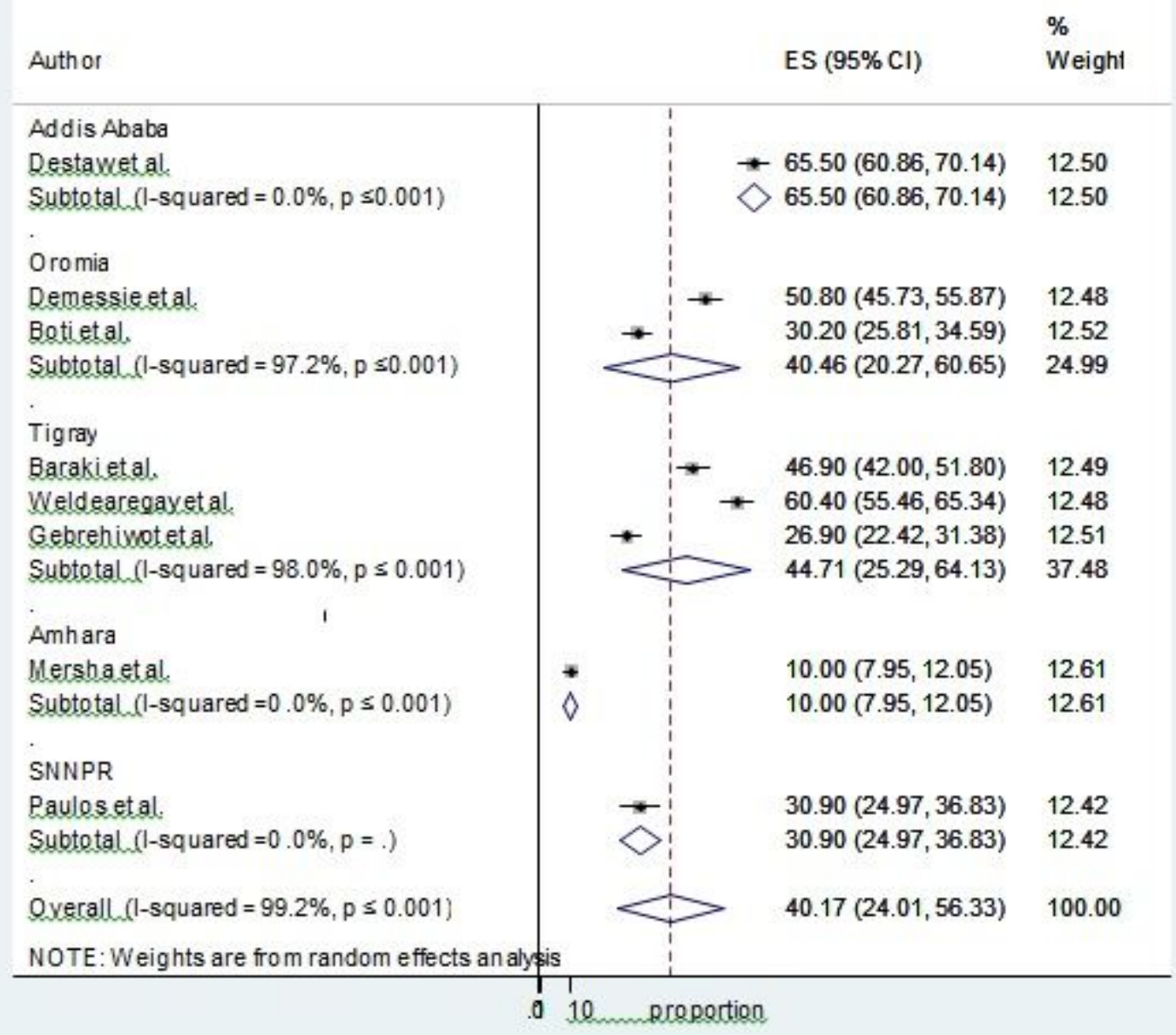

\section{Figure 3}

Meta-analysis (forest plot) for the overall all proportion of male involvement in birth preparedness and complication readiness in Ethiopia 


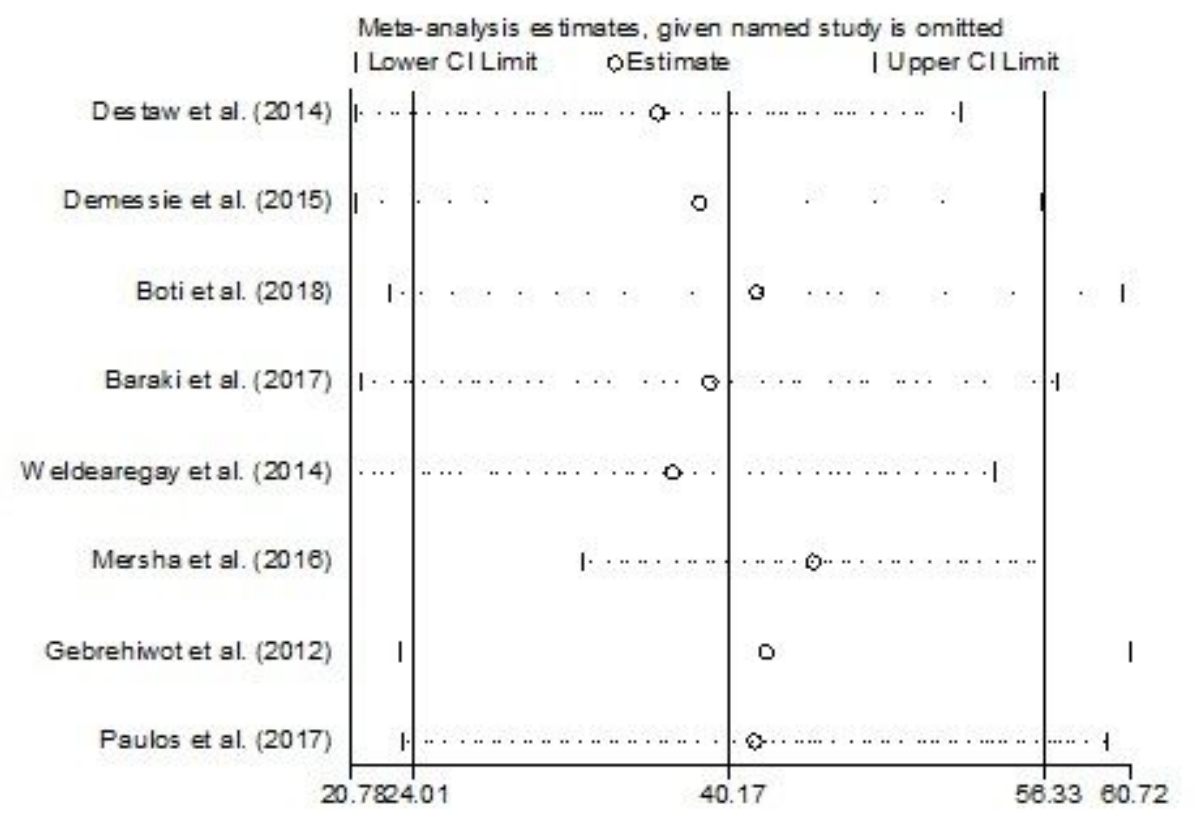

\section{Figure 4}

Sub-group analysis of the proportion of male involvement by region in Ethiopia.

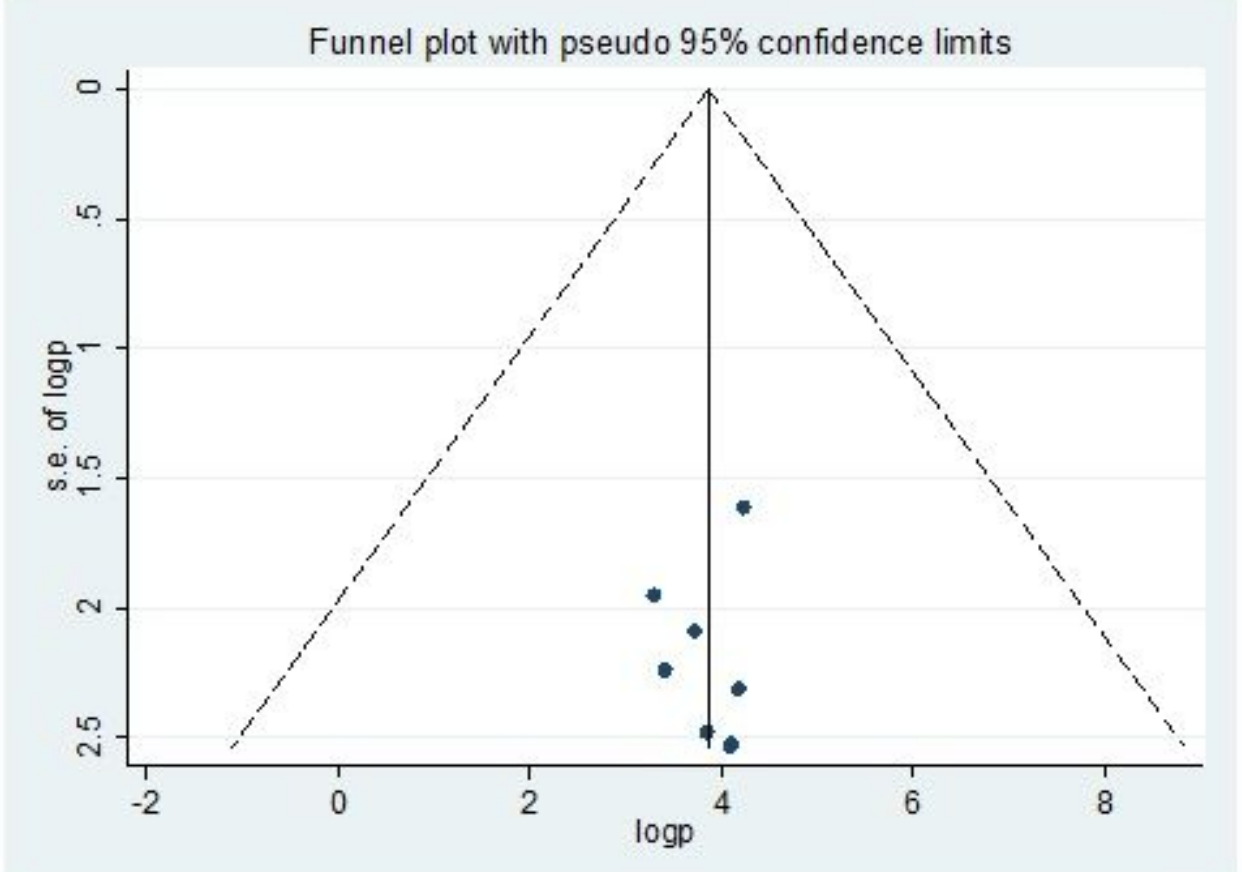

Figure 5

Funnel plot to assess the presence of publication bias for the studies included in overall analysis of male involvement in birth preparedness and complication readiness: The plot showed that there is no bias. 


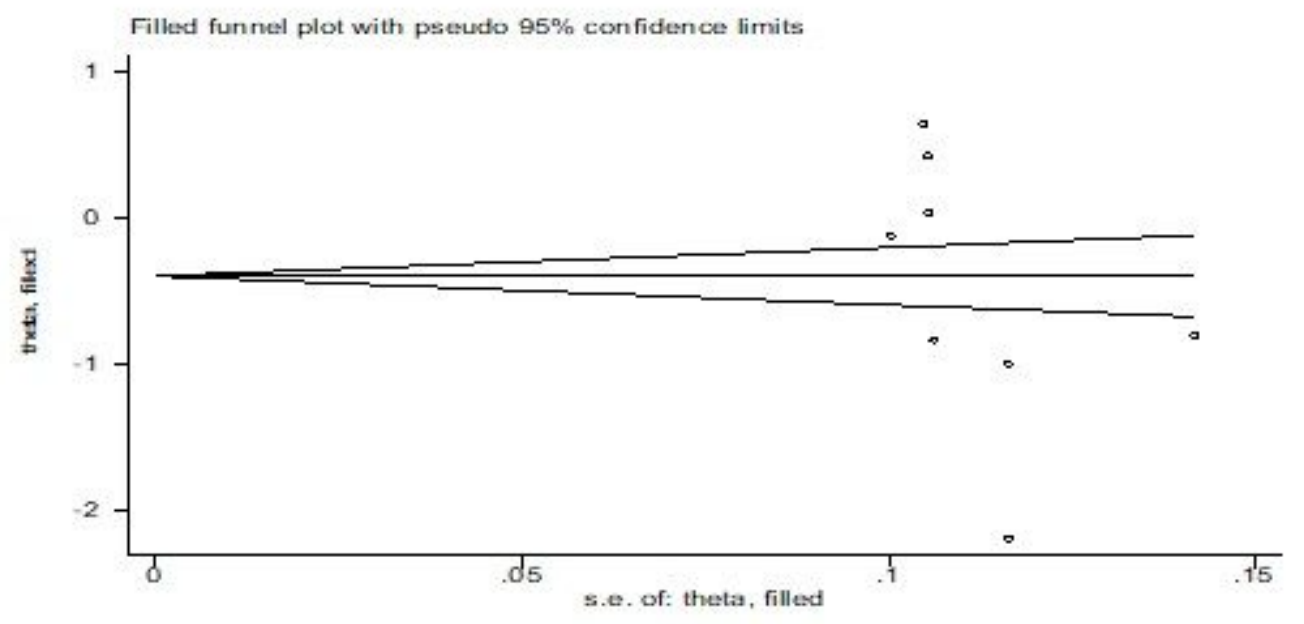

\section{Figure 6}

Filled and trim analysis

Male involvement during ANC

Study

Destaw et al. (2014)

Demessie et al. (2015)

Boti et al. (2018)

Baraki et al. (2017)

Weldearegay et al. (2014)

Mersha et al. (2016)

Gebrehiwot et al. (2012)

Paulos et al. (2017)

Qxerall_sf-squared $=99.3 \%, p \leq 0.001$ )

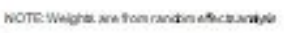
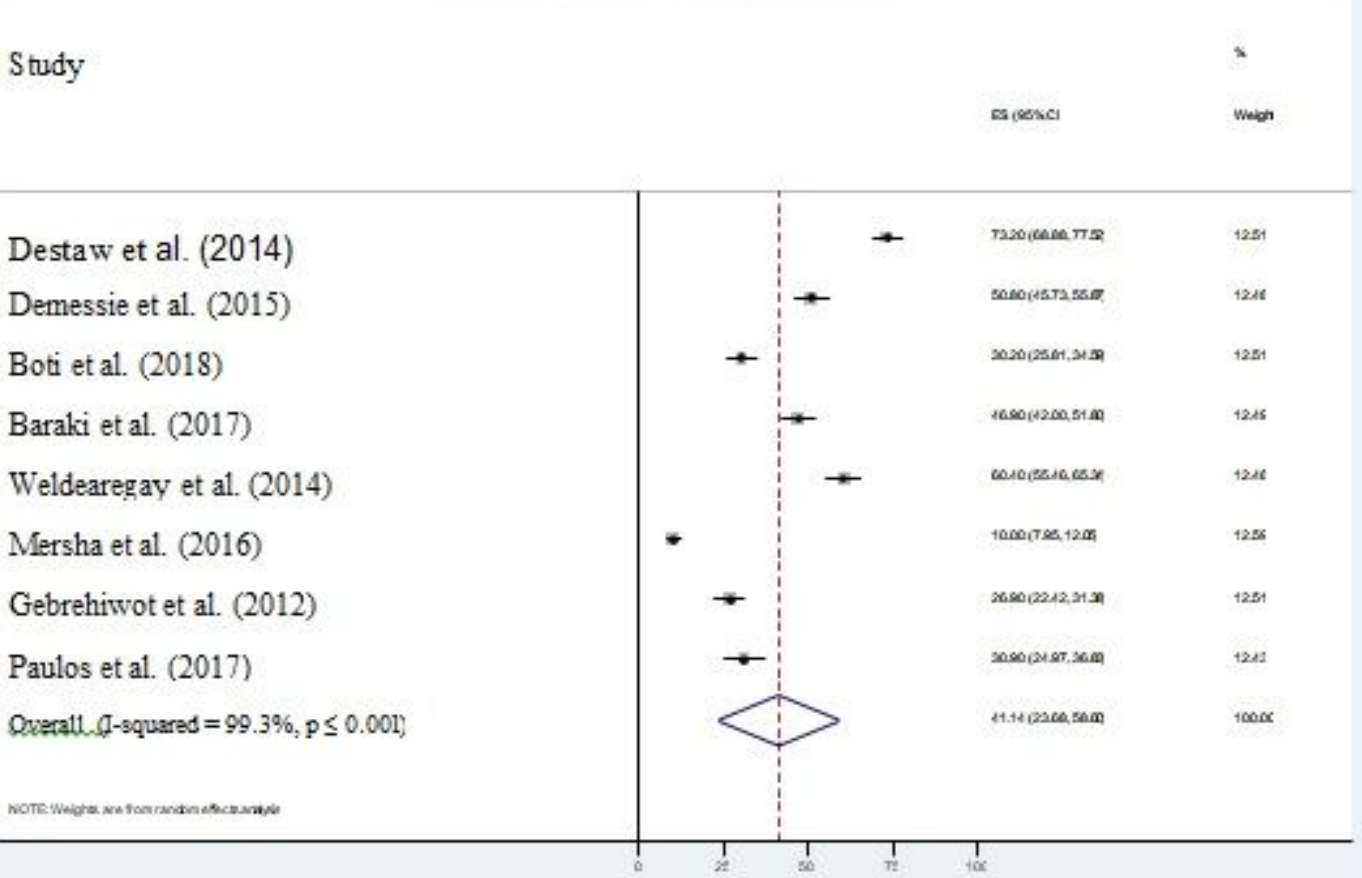

\section{Figure 7}

Meta-analysis (forest plot) for the proportion of antenatal care (ANC) involvement of males' in Ethiopia 
Antenatal care involvement of Husband's

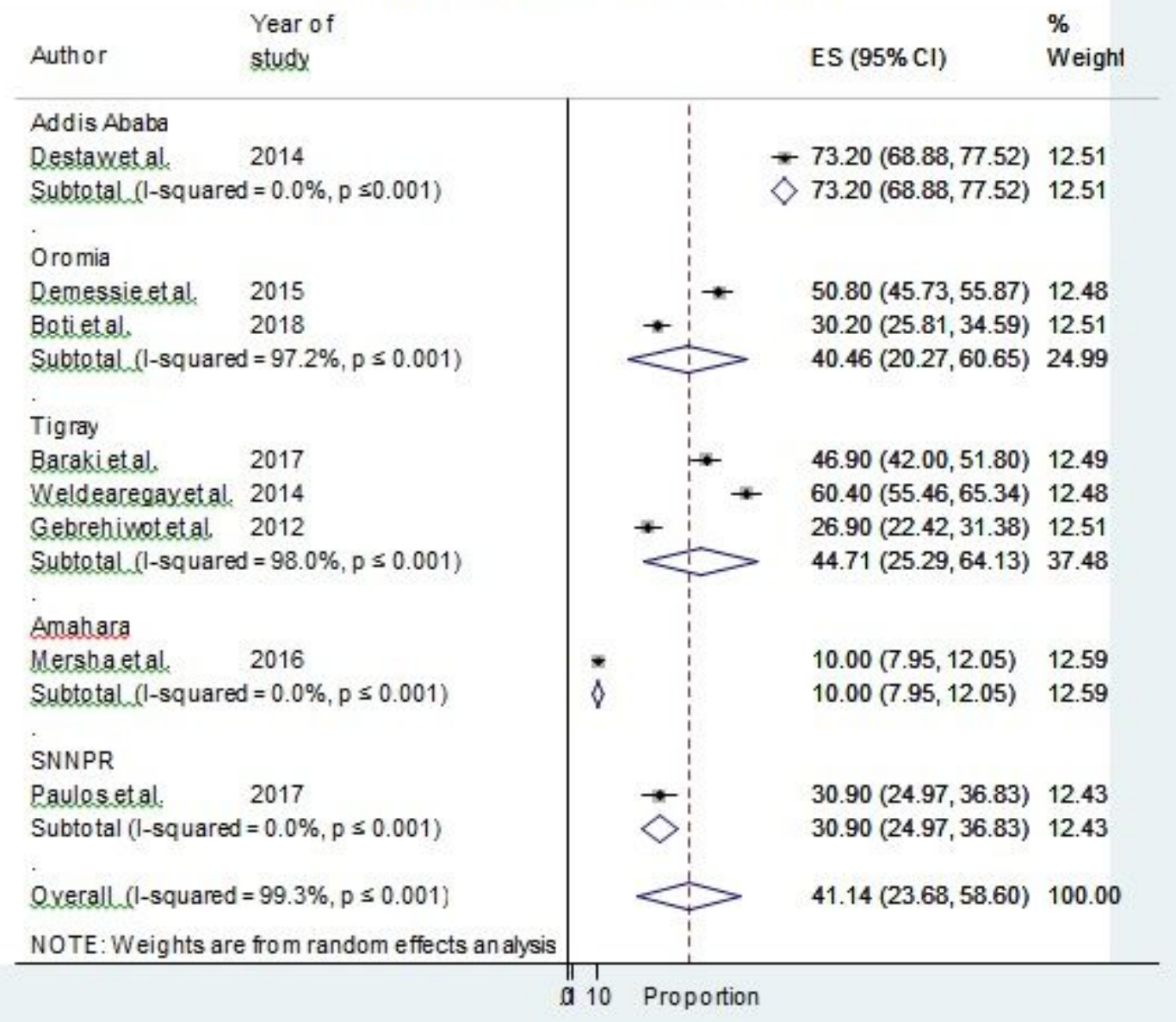

\section{Figure 8}

Subgroup analysis of male involvement during antenatal care (ANC) by region in Ethiopia 


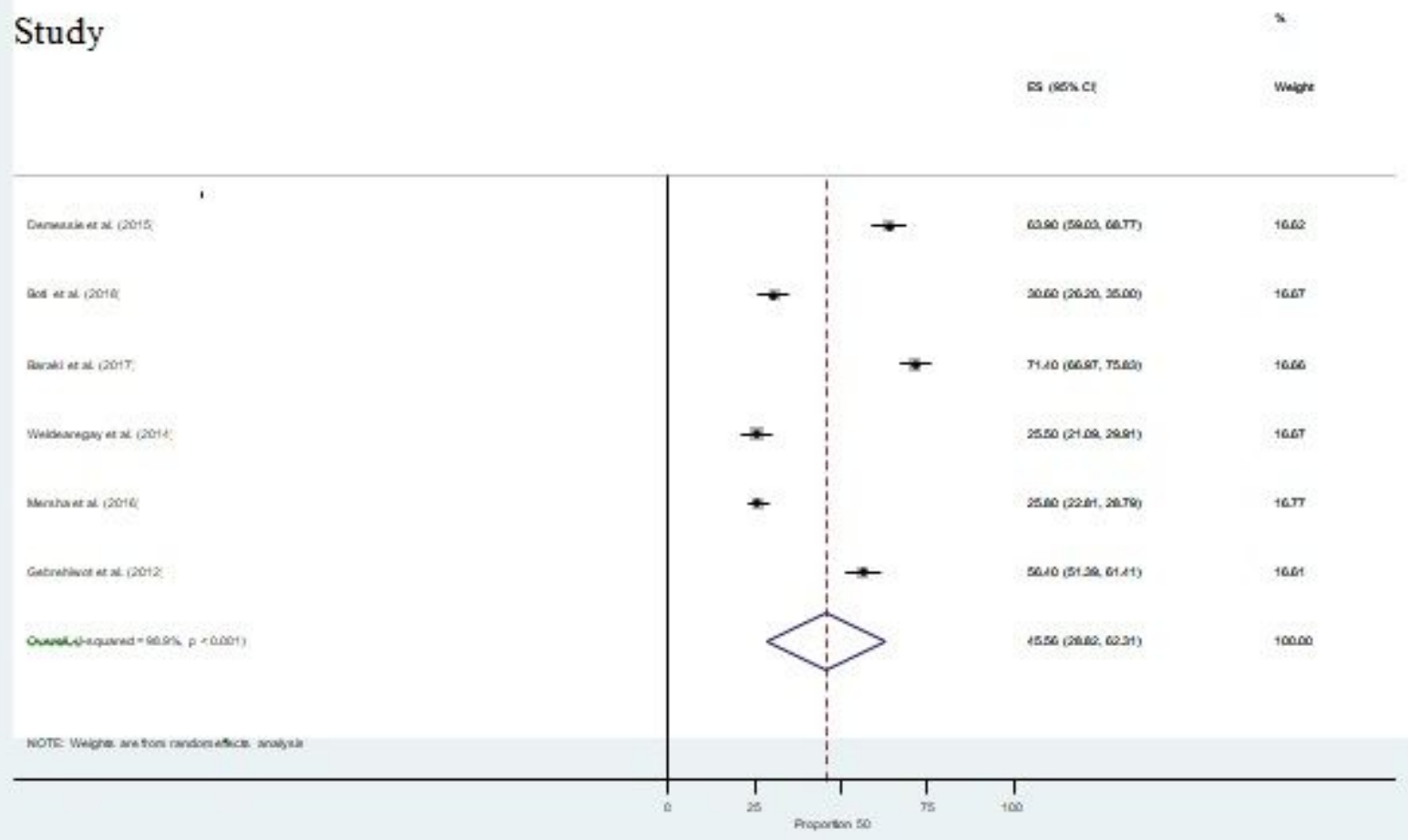

\section{Figure 9}

Meta-analysis (forest plot) of the proportion of male involvement during delivery in Ethiopia 
Subgroup analysis of male involvement during delivery

Yess of

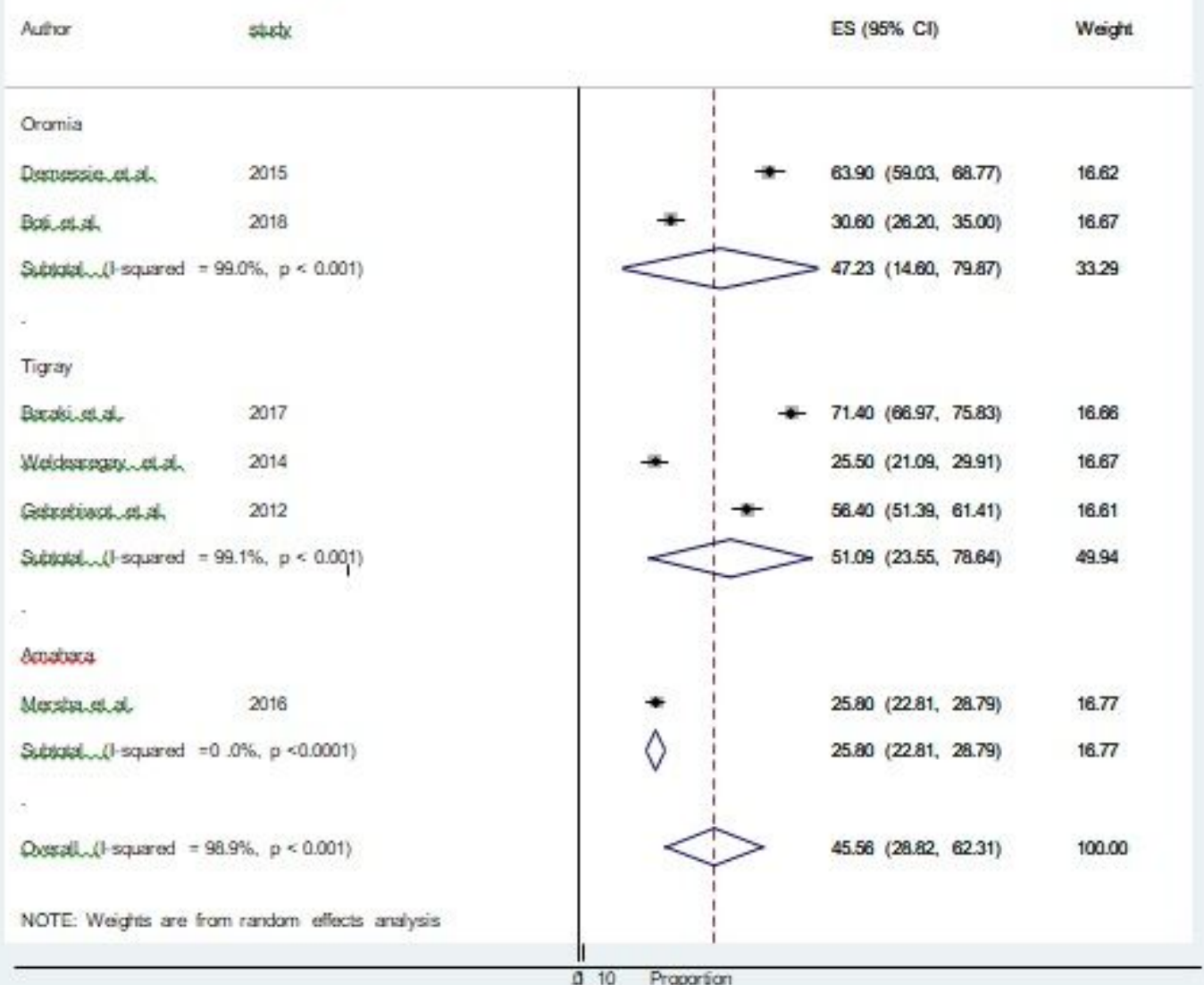

\section{Figure 10}

subgroup Meta-analysis (forest plot) of proportion of male involvement during delivery in Ethiopia 


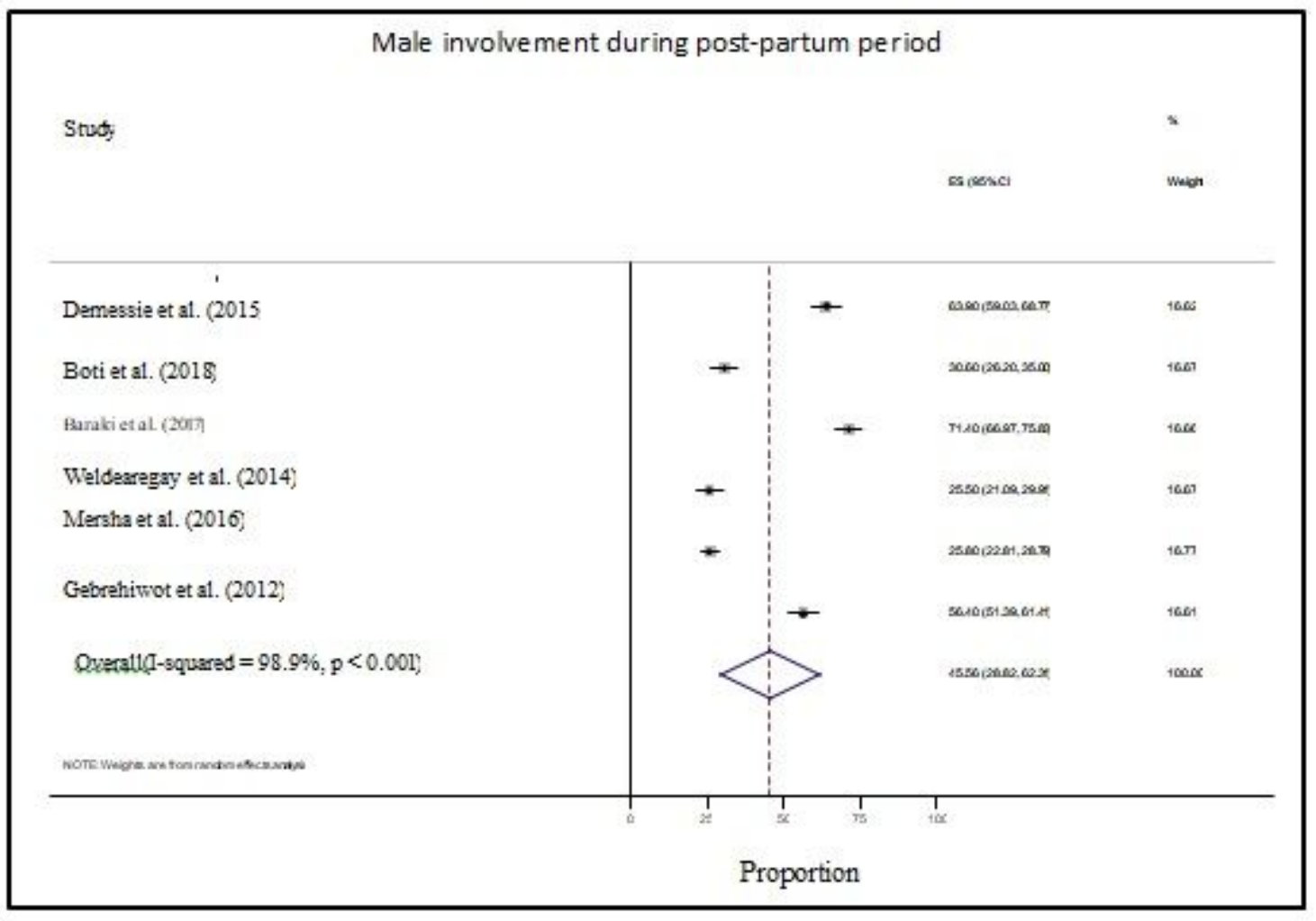

Figure 11

Meta-analysis (forest plot) of male involvement during post-partum period in Ethiopia 


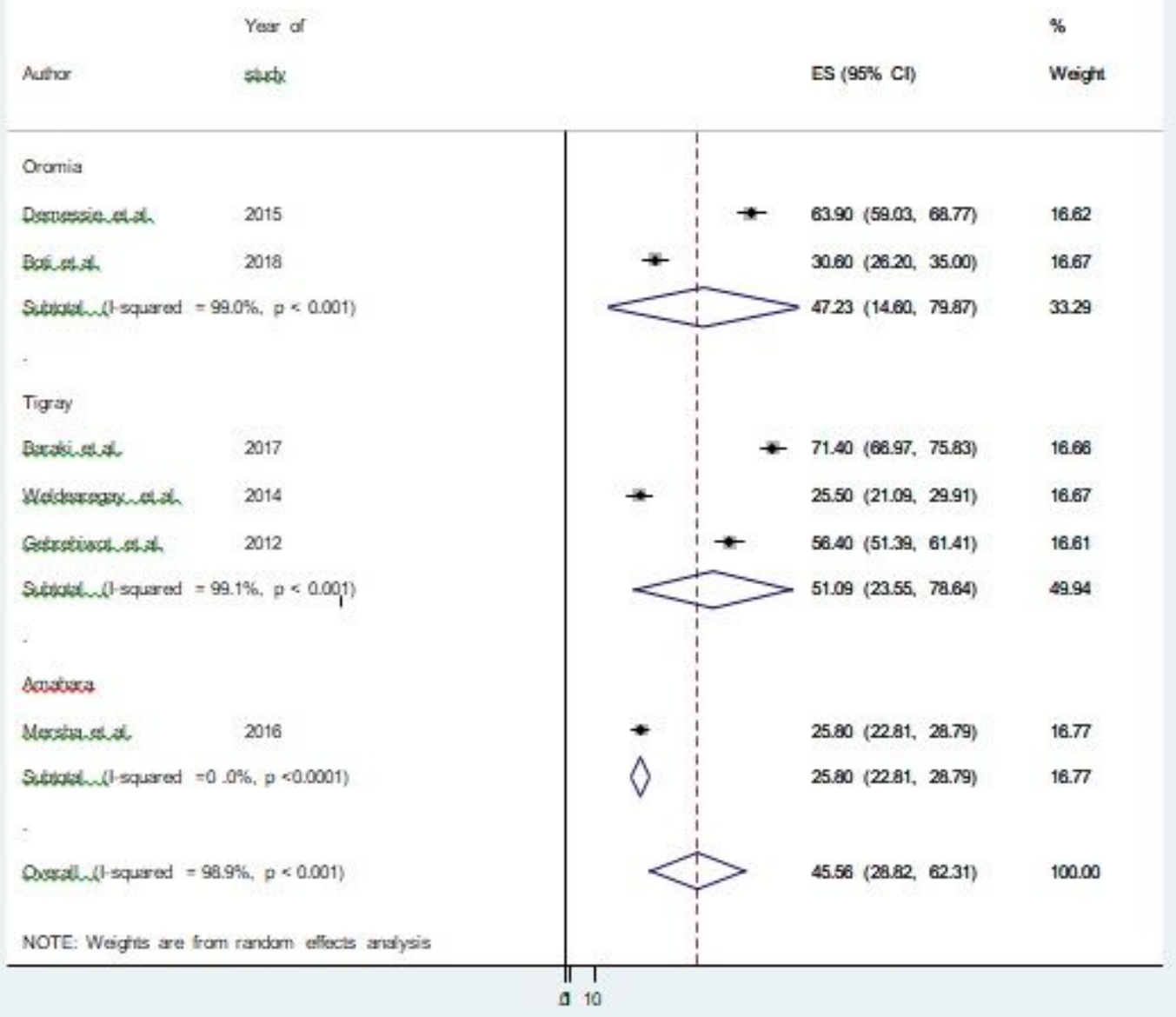

\section{Figure 12}

Subgroup analysis of male involvement by region during post-partum in Ethiopia

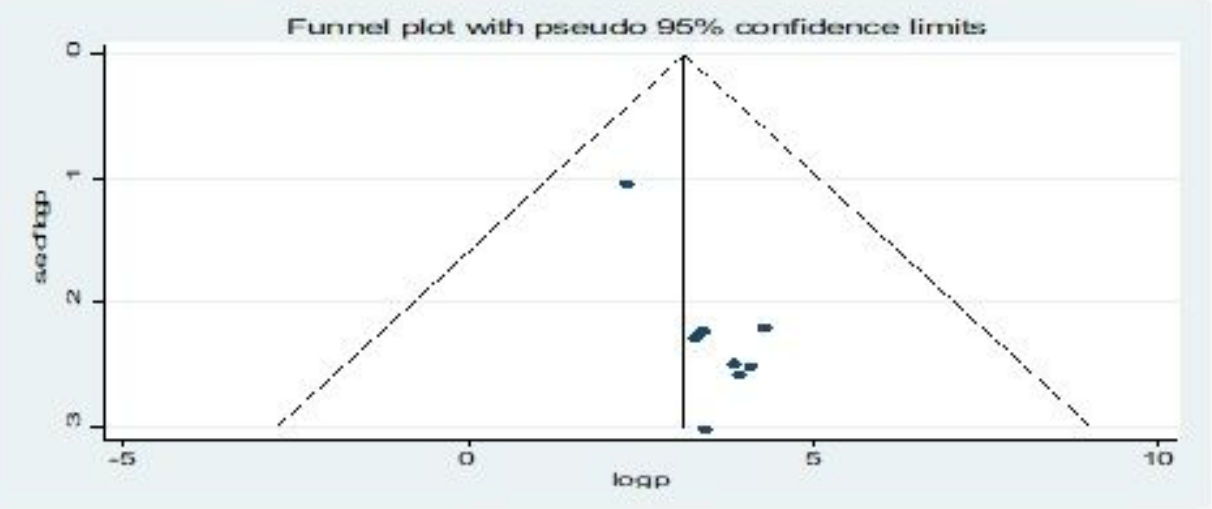

\section{Figure 13}

Funnel plot of the included studies in the meta-analysis of male involvement during antenatal care 


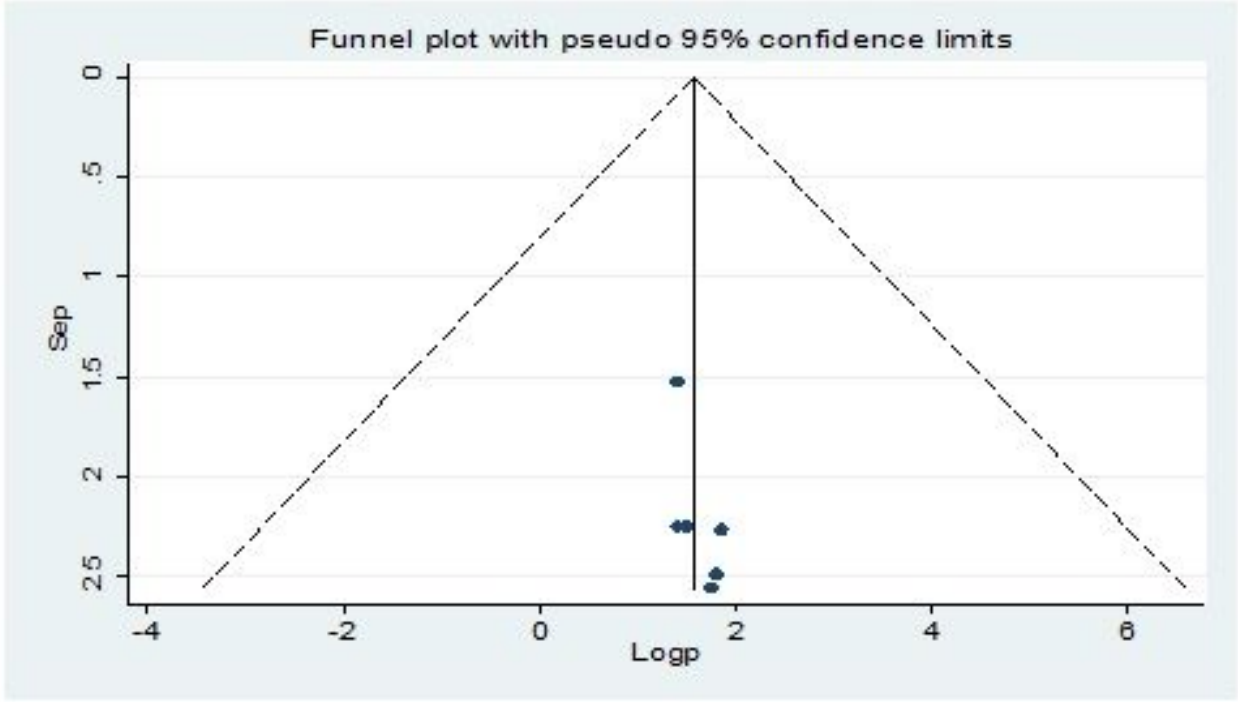

\section{Figure 14}

Funnel plot of studies included in delivery and post-partum

Husbands' level of education

Study

Author Year

Year

$\mathrm{OR}(95 \% \mathrm{Cl}) \quad$ Weigh

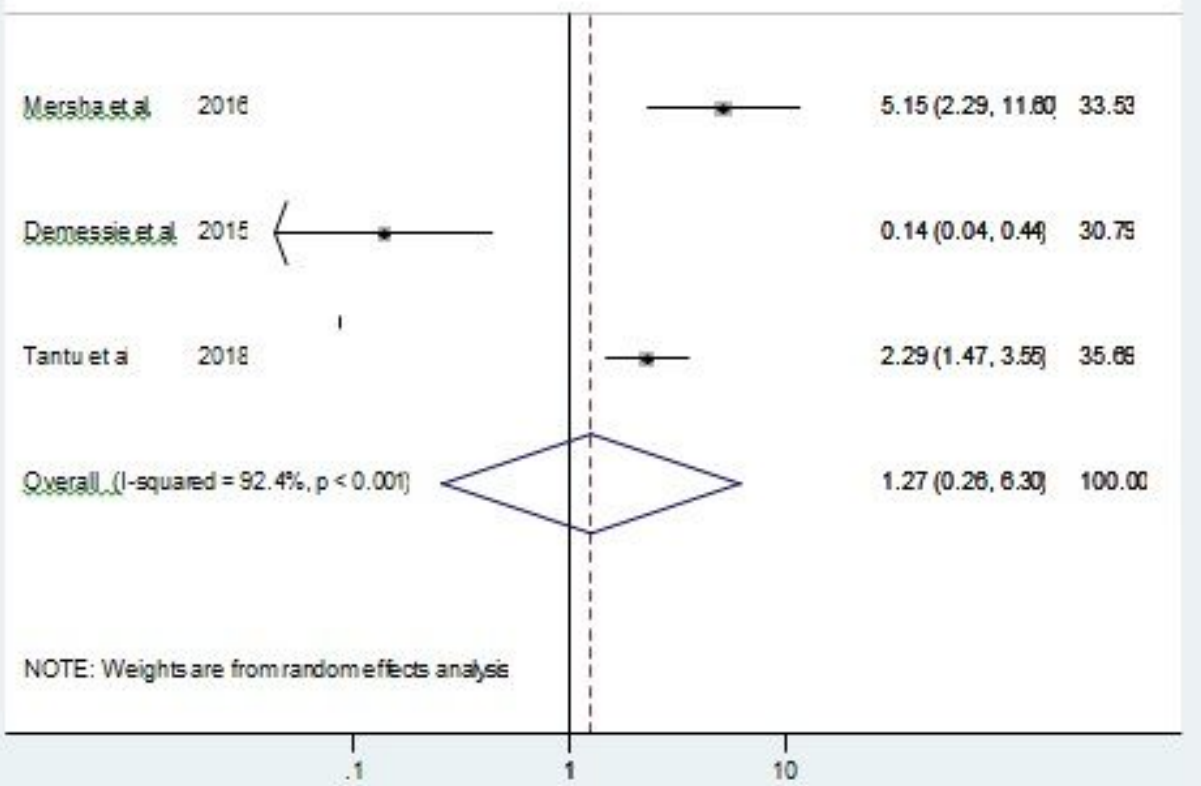

Figure 15 
Meta-analysis (forest plot) of the association between husband's levels of education with involvement in birth preparedness and complication readiness in Ethiopia

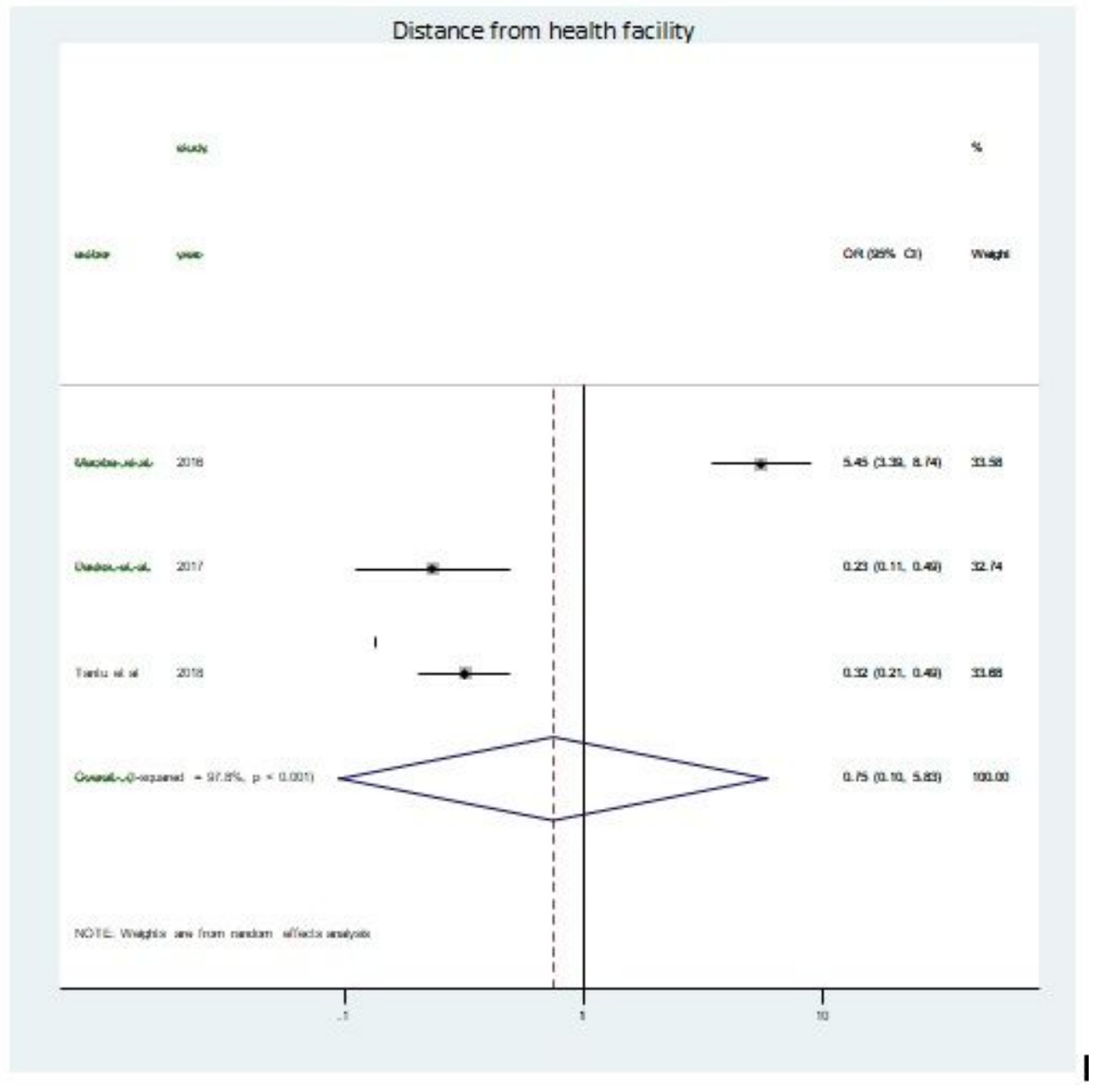

\section{Figure 16}

Meta-analysis (forest plot) of the association between distance from health facility with hus-band's involvement in birth preparedness and complication readiness in Ethiopia 
stugh

authos

Jeal
$\%$

$\mathrm{OR}(95 \% \mathrm{Cl}) \quad$ Weight

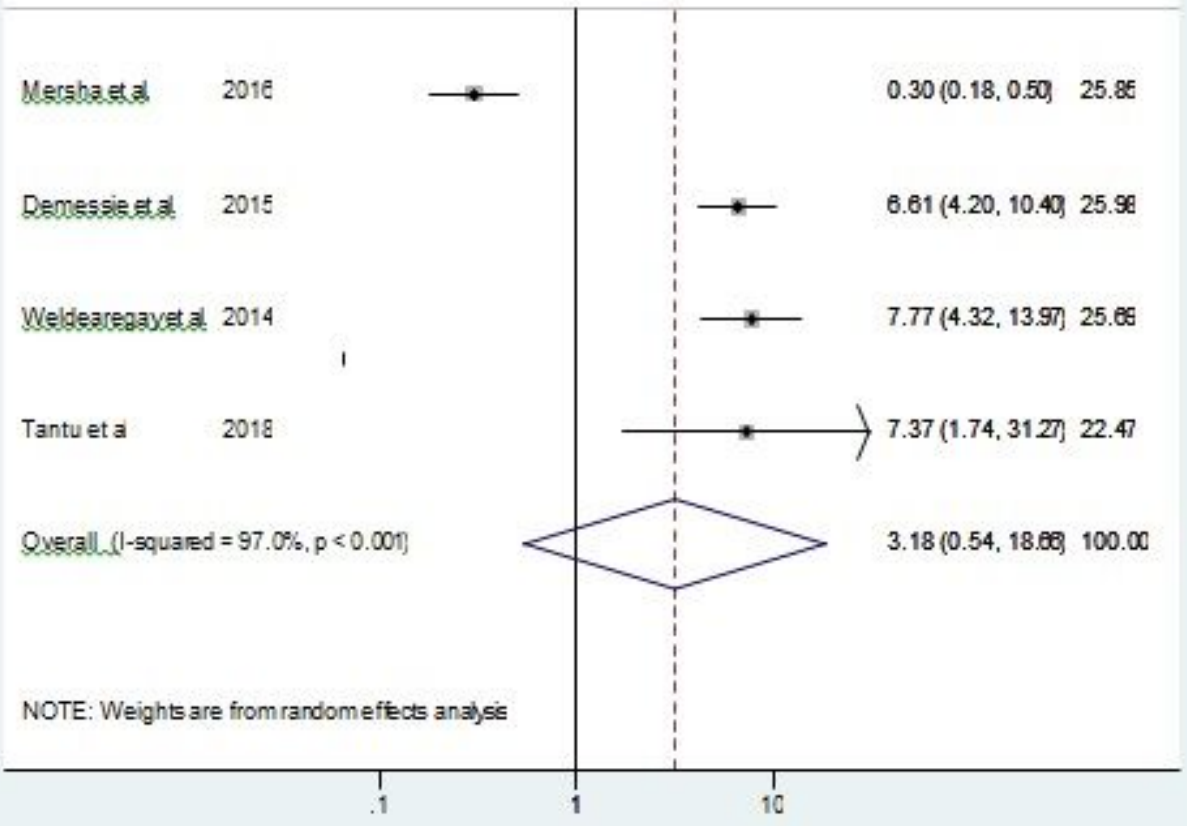

\section{Figure 17}

Meta-analysis (forest plot) of the association between husband's knowledge of danger sign and involvement in birth preparedness and complication readiness in Ethiopia 


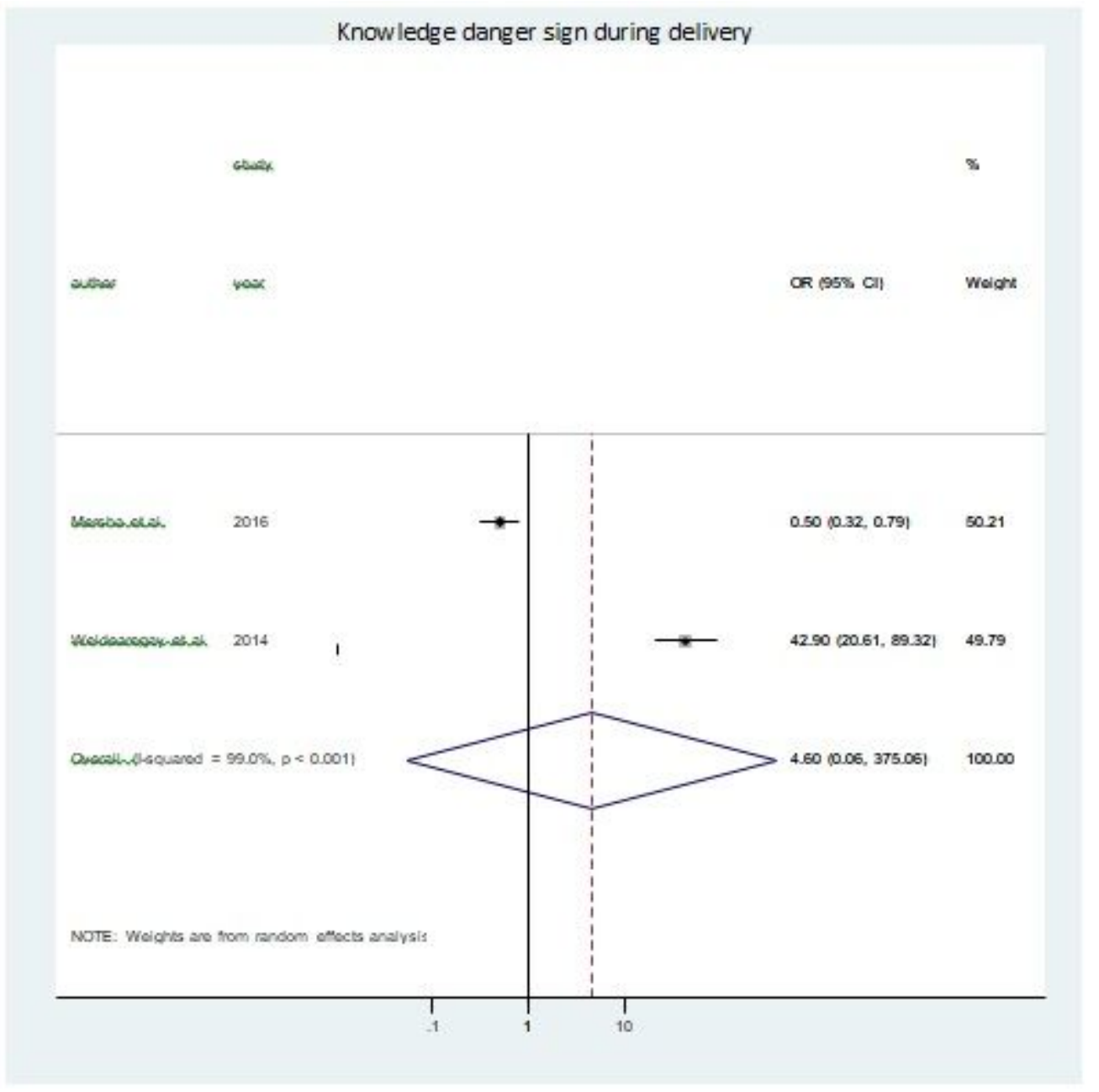

Figure 18

Meta-analysis (forest plot) of the association between husband's knowledge of danger sign during delivery with involvement in birth preparedness and complication readiness in Ethiopia 


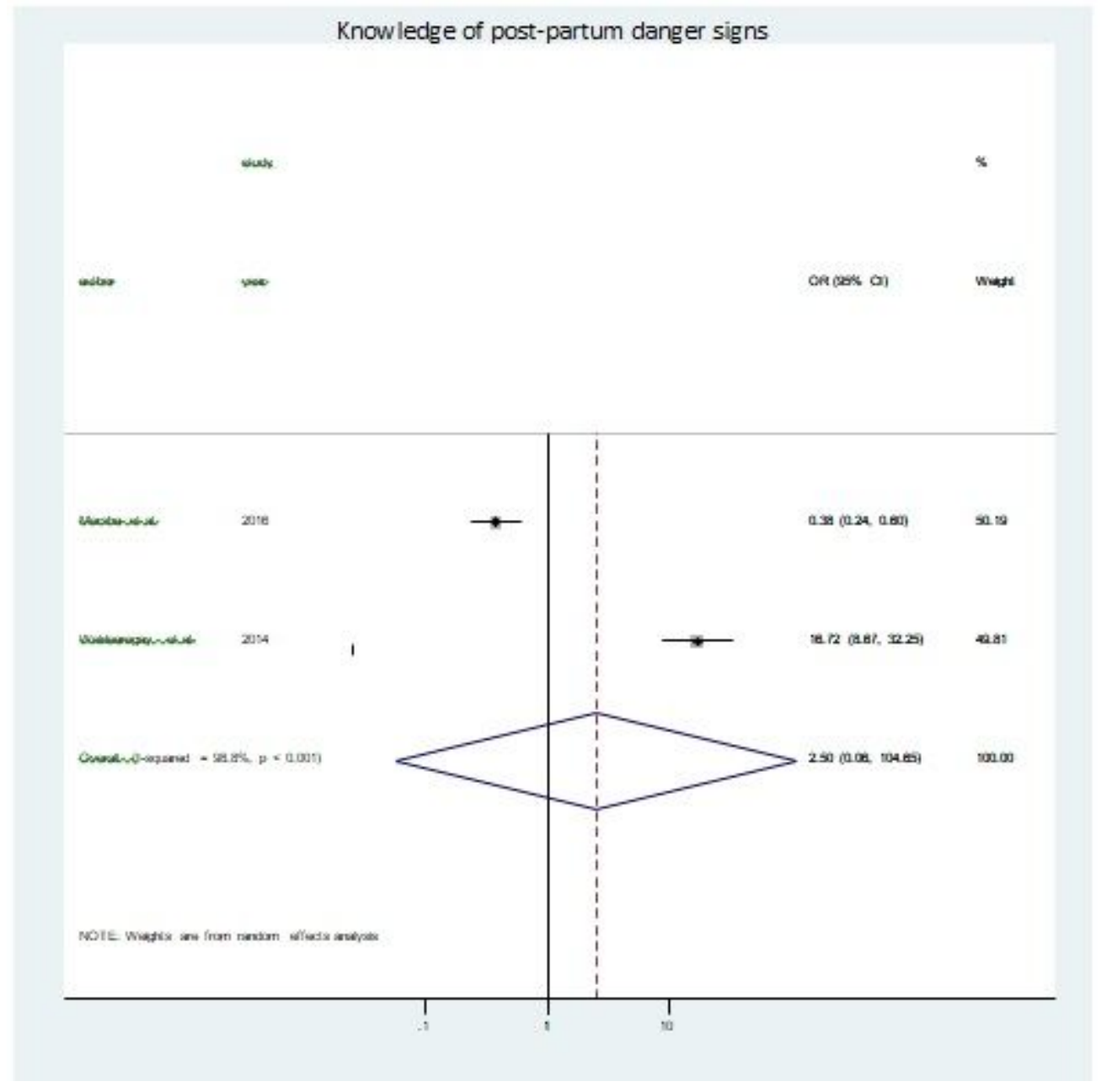

\section{Figure 19}

Meta-analysis (forest plot) of the association between husband's knowledge of post-partum danger sign with involvement in birth preparedness and complication readiness in Ethiopia 


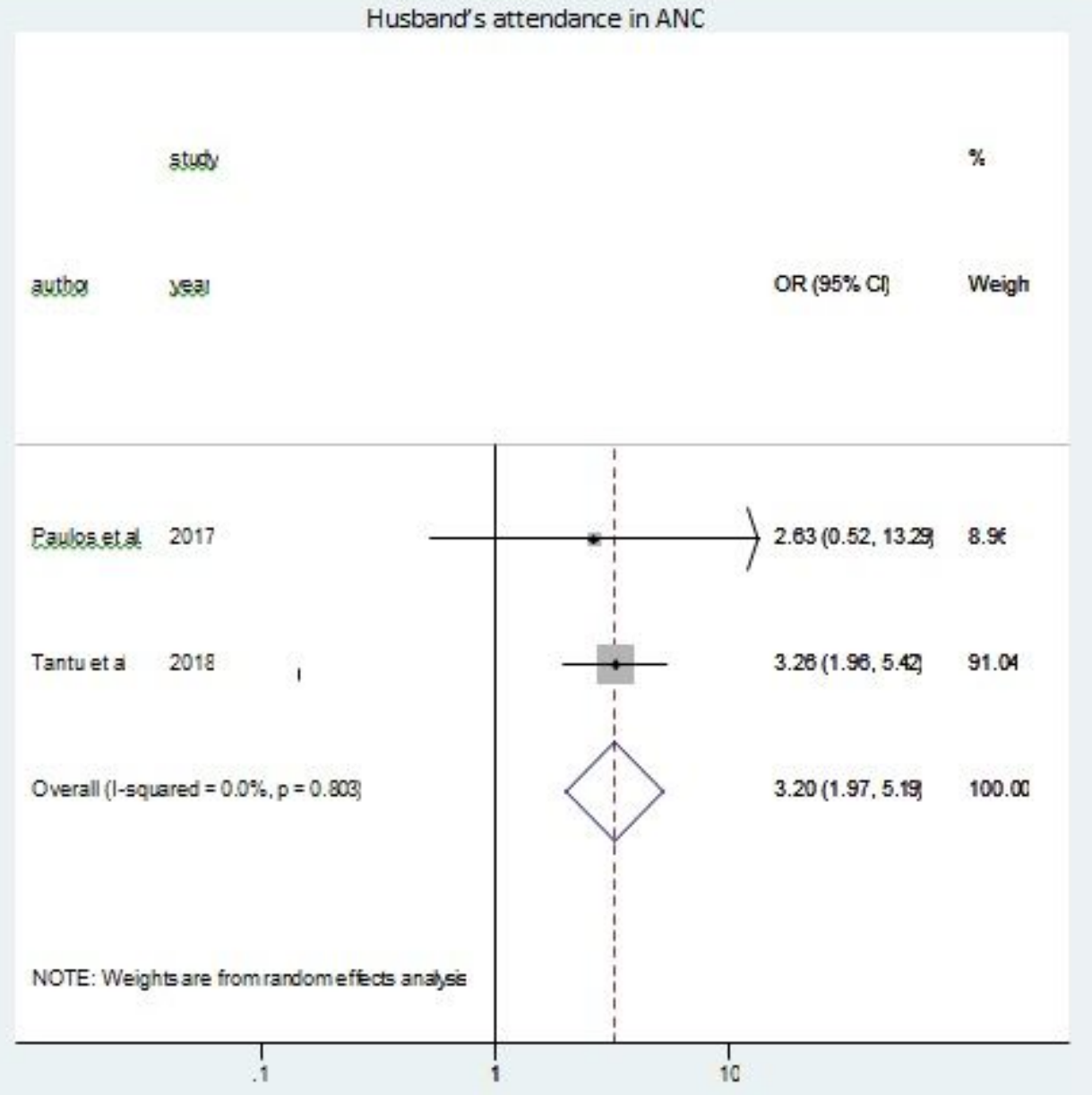

\section{Figure 20}

Meta-analysis (forest plot) of the association between husband's at least one ANC attendance with their wives and involvement in birth preparedness and complication readiness in Ethiopia

\section{Supplementary Files}

This is a list of supplementary files associated with this preprint. Click to download.

- Additionalfile1.docx 